\title{
Partnerships and Pedagogy: Transforming the BA Online
}

\section{Clare Lloyd $^{1}$, Annika Herb ${ }^{1}$, Michael Kilmister ${ }^{1}$, Catharine Coleborne ${ }^{2}$}

${ }^{1}$ Learning Design and Teaching Innovation, University of Newcastle, Australia, ${ }^{2}$ School of Humanities and Social Sciences, University of Newcastle, Australia.

\begin{abstract}
There has been much written recently round the "digital revolution" of universities (Nascimento Cunha et al., 2020). Indeed, in 2020 the COVID-19 pandemic demonstrated the need for universities to adapt and adopt new technological tools for teaching and learning, as both the global world we live in changed, and as students adapted to the continually evolving digital landscape. The BA Online is a new interdisciplinary online presence for the humanities and social sciences, and includes a focus on constructive alignment, innovative learning objects, and social learning. The semester-long courses were built as a supported social learning experience that is purposefully constructed with a narrative. This article reveals how the BA Online project was realised through the use of partnerships, particularly that of the university learning designers who worked very closely with both the online learning platform FutureLearn and academic staff in curriculum design and course transformation.
\end{abstract}

Keywords: Online learning; partnerships; pedagogy; digital learning; TEL; learning design. 


\section{Introduction}

The pre-2020 landscape for online learning in the global higher education sector suggested that universities were facing new challenges to formats, delivery modes and student experience outcomes. The arrival of COVID-19 intensified these demands. Some commentators are positing this as a multi-faceted transformation of education, a set of changes happening across technology and degree models, as well as educational offerings from non-university higher education providers (Nascimento Cunha et al., 2020). A sustained interest in massive open online courses (MOOCs) over the last decade has morphed into debates about "unbundling learning" (disaggregating qualifications into their component parts). Recently, the conversation has been directed at how technological "disruption" is changing the higher education sector. Disruption is transformational and problematic for the sector because it challenges some precepts of the higher education institution as a space and place of learning, especially following decades of investment in on-campus student experiences. The disruptive technology involved in online learning "is at work in higher education, allowing both for-profit and traditional not-for-profit institutions to rethink the entire traditional higher education model. Private universities without national recognition and large endowments are at great financial risk. So are public universities, even prestigious ones" (Christensen \& Eyring, 2011, p. 18). If this threat of dramatic change to the sector is realised, we can assume we need to continue to think about the role played by open online courses and other online study options.

Bachelor of Arts (BA) degrees in Australia have received much attention over the past decade. National research about the value and relevance of the undergraduate "liberal arts" in the Australian context reveals the need for new pedagogical approaches (see Gannaway, 2015). There is also recognition for the degree competencies in the current higher education context, including support from business, science, and technology leaders (Doidge \& Doyle, 2020). Challenges include thinking about new ways to present disciplinary content. At the University of Newcastle (UON), the BA degree program needed reinvention to meet the manifold challenges facing the humanities and social sciences (HASS) sector at large, including shrinking funding pools and fluctuating enrolment numbers (Turner \& Brass, 2014). This process of change had been progressively in motion at UON since 2016. This meant teamwork to redesign the core curriculum of the degree and innovate teaching approaches, including a strong emphasis on multidisciplinary, inquiry-based and social learning. These processes allowed the team-comprised of professional and academic staff from different areas of the University, mainly HASS and the University's learning and teaching unit, Learning Design and Teaching Innovation (LDTI) - to introduce new intellectual and creative energy into a long-established degree program. Transformation of the degree required specific interventions including engaging with new digital online learning platform and external partner, FutureLearn. This article showcases the project we 
commenced in partnership with FutureLearn, and reflects on this relationship to date and its teaching and learning outcomes. By making UON's processes and partnerships visible - and the lessons learned along the way —we aim to inform other universities' efforts to rejuvenate HASS programs.

The project required the identification of majors for online delivery and signalling a new identity for this degree for global and national learners. The process of designing courses for online delivery, creating quality content, and embedding intuitive interaction has been a collaborative project operating at scale. In particular, we focus on the role of the university learning designers who worked closely with the FutureLearn platform, encouraged academic staff involved in curriculum design and transformation, and were deeply involved in decision-making informed by expectations surrounding quality assurance. FutureLearn's pedagogy-first philosophy enabled fresh ways of imagining the teaching of humanities content and assessment, including developing and employing online curriculum design principles. In this article, we outline the process of developing UON's online BA degree, our collaboration with FutureLearn, approaches in collaborative design within the institution, and the project's broader implications for pedagogy and online learning in humanities.

\section{The FutureLearn Partnership: A new BA (online)}

Recently, there has been a shift of focus for the education technology sector from what and how each technology might "disrupt" the higher education sector to "much more about how the teaching and learning process is being changed by edtech" (Field, 2019, para. 1). This means educators must now knowingly make choices in their teaching design about how content, learning outcomes, and assessment are constructively aligned (in other words, aligning teaching and assessment to the outcomes we want students to achieve). Hunt et al. (2012) address shifts in higher education that have resulted in increased engagement with online learning, arguing pedagogy is shaped by both physical and virtual spaces. Examining a case study at the University of Southern Queensland, the authors note the importance of deliberate design with consideration to pedagogy. Online learning has been increasingly celebrated, but also scrutinised, as universities seek to develop meaningful learning experiences for students in the context of learning with digital technologies. Using a case study from the University of Leicester, Salmon (2011) identifies and evaluates the processes involved in designing and executing a new learning innovation strategy focused on online learning. She emphasises the need for a combination of radical and incremental innovation. Here, Picciano (2017) proposes an integrated model for online education, which requires "the phenomenon of pedagogically driven online education. Key to this model is the assumption that online education has evolved as a subset of learning in general rather than a subset of distance learning" (p. 187). One way the humanities disciplines at the University of Newcastle are embracing and leading in this field is engaging with technology-enhanced 
learning that is driven by strong pedagogical design for social learning. It is clear from the literature - and our experiences in this space - that it is important to assert that academics should not consciously use technology for its own sake, but rather to think about equitable access to quality education with a good student learning experience at the centre of learning design.

The pursuit of pedagogy-led online learning brought UON into partnership with FutureLearn. Launched in late 2013 by Open University (UK) with only "open courses" (MOOCs), in recent years it has broadened its range of education options with degrees-mainly postgraduate - and more recently, microcredentials. Pedagogy is at the fore of FutureLearn's research and development, with partners encouraged to adopt the platform's social learning philosophy. FutureLearn has expanded its footprint in Australia in recent years, partnering with 17 Australian universities at the time of writing. The principles the platform is designed around are "learning through storytelling", "discussion for learning", "visible learning", and "community supported learning" (FutureLearn, 2020). In other words, FutureLearn has been intentionally underpinned by a social constructivist approach (Swinnterton et al., 2017).

The University of Newcastle signed with London-based FutureLearn in mid 2018 with the key intent of utilising the platform for the delivery of four majors of the BA Online. An objective of the BA Online is to offer a contemporary, multidisciplinary degree that widens avenues for higher education participation, especially for non-traditional students. The renewed degree enables this access by affording greater flexibility in delivery mode. Additionally, it includes a focus on constructive alignment and innovative learning objects with high production values. This was also a new endeavour for FutureLearn: the BA Online was their first undergraduate degree. The partnership was realised with the launch of the first 6 courses in early 2019 (Semester 1 in Australia); in total, 35 courses are scheduled to launch over the 3 years of the project. (Courses are 12 week semester-long units of study). The scale and newness of this project were daunting, but moving to an online degree with FutureLearn was necessary to increase high-quality, online, and flexible study options for our incoming and current students.

\subsection{Moving the $B A$ degree online}

A Bachelor of Arts is traditionally a flexible degree in terms of course selection, essentially allowing students to create their own path. The BA Online at UON is a degree for students interested in studying a selection of majors, minors and courses fully online. Students can either opt to take their degree completely online, or choose some online courses and some face to face, giving students flexibility. The courses for the four majors-Film, Media and Cultural Studies; English and Writing; History; and Sociology and Anthropology — and the BA core courses are being progressively developed and delivered between 2018 and 2021. Integrating FutureLearn into existing enrolment and teaching systems has its challenges. 
Therefore, courses on the platform still launch from the learning management system (LMS), which is used for summative assessment and for administrative tasks, whereas FutureLearn is used for content delivery and discussion.

Courses redesigned for online delivery via FutureLearn comprise specific learning components (see Fig. 1). For example, each course has four modules (each 3 weeks long). The majority of the first-year courses also have the first module as a "open" course on FutureLearn. Both UON students and FutureLearn learners have access to this 3 week module. The other three modules are "closed" or "for credit", where learners need to be UON students (Award or Non-Award) to be able to complete the final three modules of the course.

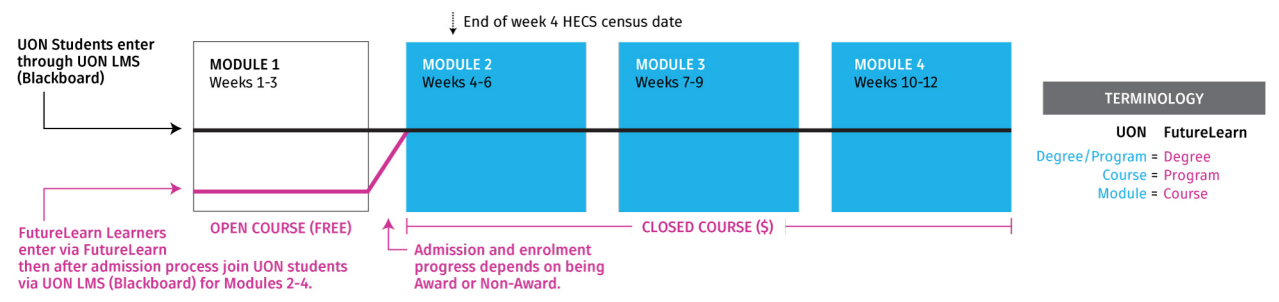

Figure 1. Diagram showing the student entry points for the BA Online at the University of Newcastle.

\subsection{Transformative Practices: The Role of Learning Designers}

Developing online courses with experienced academic staff can create challenges that arise from seeking to change embedded teaching practices in a domain in which they are well established and/or credentialed. Indeed, working with academic resistance and indirectly furthering educator development are topics that would benefit from further enquiry. In the traditional lecture theatre or tutorial space, academics are generally unused to another party reviewing their course content and teaching style and recommending best practice (Brigance, 2011). Additionally, teaching staff who are unfamiliar with online course delivery often have little insight into what learning designers can do to help them to facilitate involved and interactive learning experiences (Hsu, 2020). The complexity of designing learning for online environments at the tertiary level is summed up by McInnes (2019):

The ability to produce instructor-centric multimedia, which cuts together contentcentric materials as necessary, is a resource-intensive process which requires a significant amount of planning, time and training. Whilst this is a process that is ideally suited to the supportive nature of the collaborative team approach, it is a complex process and as such the resource constraints of large-scale intensive curriculum development mean that developing instructor-centric styles of multimedia can be difficult (p. 10).

Sims et al. (2002) argue that planning and design in online learning needs to involve proactive evaluation and participatory partnerships. This means, personnel involved in course design- 
both learning designers and course coordinators - should develop a shared understanding of the design steps needed to accomplish "the complex interaction between disciplinary content, learning outcomes and online learning environments" (Sims et al., 2002, p. 137). One of the most significant pedagogical challenges we faced in transitioning humanities courses to FutureLearn lay in what we call "unbundling the traditional humanities tutorial". This meant that we had to adapt the traditional Socratic method of tutorials and lectorials to an onlineonly learning environment. The Socratic method, as the name suggests, revolves around Socratic questioning - challenging students' thinking through a series of questions designed to elicit more than yes/no responses, probing their answers with further enquiries, and ultimately encouraging them to defend or change their position. While Socratic questioning can prove effective in online teaching (Picciano, 2017), issues can arise when considering the asynchronous learning style encouraged by FutureLearn.

The role of the learning designer and their relationship with the course coordinator in this project has been significant. Hsu notes that although the learning designer's "role and the composition of their tasks might vary across institutions, their involvement in helping faculty design and develop online or blended course content becomes vital"' (2020, p. 50). The team has found little need to be too prescriptive with the type and style of planning, instead enjoying collaborative planning, modelling content design, and facilitating the planning phase through workshops and meetings, all of which have all been demonstrated to work. Individual academics have brought different experiences and challenges to bear on these interactions. The learning design team has arrived on standards for planning processes which are negotiated with the academics in a collaborative process. Courses with multiple people involved in the planning especially demand a cloud-based document-sharing platform for content decision-making. Otherwise, we suggest, the task of planning a course becomes unmanageable and challenging to replicate at scale.

Incorporating pedagogy at the core of development of courses, the learning designer worked collaboratively with the course coordinator in workshops to develop or redevelop a course for an online learning context. The learning designer and course coordinator developed a course plan, modularising content, before breaking down the key concepts of each week. This plan was constructively aligned by jointly determining the learning outcomes of each week, dividing these into "activities". Each activity incorporated opportunities for active, social learning, as students were introduced to a topic by a video or text article, applied the concept, reflected on the topic, and produced outputs with their new skills. Regular opportunities for reflection, feedback, or further instruction were included, with in-built comment sections for each step. Some steps included discussion prompts to guide reflection, whereas others were left open to allow students to extend their ideas and facilitate open discussion. The learning designer and course coordinator developed videos, audio, text, and other multimedia. The learning designers sourced innovative digital tools, with an emphasis on those that were 
genuinely beneficial or could be tailored to course aims and learning outcomes. These aided the asynchronous learning environment, where students could return to tasks and engage in social learning practices throughout the week.

Reflecting on experiences in the learning design phase is vital to ensuring the staff evaluated and evolved their approach from their own experiences and that of their team members, accommodating for a range of pedagogical approaches between academics. They reflected on student experience and feedback from surveys to review and update the courses. The project to reinvent the degree has also resulted in a tangible culture shift for academics in the institution who have been encouraged to think freshly about their pedagogies and disciplinary content.

\section{Conclusion}

Working on a large-scale online teaching and learning project requires a partnership approach, both between the university and the learning platform, and the collaborative relationship between academic and learning designer. The strengths of this approach are evidenced in the positive student feedback and experience. The collaboration between academics, the learning design team and FutureLearn has meant students' learning experiences have been transformed. It has demonstrated how learning in the online environment can be social, can be high quality and engaging. These partnerships have allowed for our own "disruption" of learning, employing innovative technology to reconsider how we teach the humanities in an evolving educational space. Additionally, the project placed the degree and teaching academics in a strong position for the required pivot in teaching during the COVID-19 shutdown in 2020.

Key takeaways from the project have highlighted the benefits and the importance of working with a whole program approach (and not just a single course) and the advantages of having a flexible and collaborative course development framework/method. Following the success of social learning on FutureLearn, and reinvigoration of their pedagogical approach, some academics have revisited their approach to teaching and learning in a face-to-face environment as well, incorporating the tools and practices used to create an informative social learning experience online in their face-to-face classes. The BA Online has been a force for a step change for staff and students alike, with the added benefit that learners become part of a global classroom in the open courses, meeting another aim for the BA degree in Australiato internationalise our arts degrees. The collaboration between FutureLearn, academics, and the learning design team has meant students' learning experiences have been transformed. The University of Newcastle's BA Online proves that humanities learning in the online environment can be a social, high-quality and engaging experience. 


\section{References}

Brigance, S. K. (2011). Leadership in online learning in higher education: Why instructional designers for online learning should lead the way? Performance Improvement, 50(3), 4348. doi:10.1002/pfi.20262

Christensen, C. M., \& Eyring, H. J. (2011). The innovative university: Changing the DNA of higher education from the inside out. San Franciso, CA: Jossey-Bass.

Field, C. (2019, June 25). EdTechXEurope 2019 - reflections. Claire Field \& Associates. Retrieved from https://www.clairefield.com.au/wpcontent/uploads/2019/07/EdTechXEurope-2019-reflections-final.pdf

FutureLearn. (2020). Learning on FutureLearn. https://www.futurelearn.com/usingfuturelearn/why-it-works

Hsu, H-C. K. (2020). Developing online engineering courses: A resource kit for collaboration between faculty and instructional designers. Journal of Educational Technology Systems, 49(1), 49-58. doi:10.1177/0047239520905773

Hunt, L., Huijser, H., \& Sankey, M. (2012). Learning spaces for the digital age. In M. Keppell, K. Souter, \& M. Riddle (Eds.), Physical and virtual learning spaces in higher education (pp. 182-197). Hershey, PA: Information Science Reference.

McInnes, R. (2019). Developing multimedia collaboratively: Practical approaches for largescale online curriculum development. Journal of University Teaching and Learning Practice, 16(1), 1-12. Retrieved from https://ro.uow.edu.au/jutlp/vol16/iss1/8

Nascimento Cunha, M., Chuchu, T., \& Tafadzwa Maziriri, E. (2020). Threats, challenges, and opportunities for open universities and massive online open courses in the digital revolution. International Journal of Emerging Technologies in Learning, 15(12), 191204. doi:10.3991/ijet.v15i12.13435

Picciano, A. G. (2017). Theories and frameworks for online education: Seeking an integrated model. Online Learning, 21(3), 166-190. doi:10.24059/olj.v21i3.1225

Salmon, G. (2011). Learning innovation for the 21st century. In Ehlers U. \& Schneckenberg, D. (Eds.) Changing cultures in higher education: Moving ahead to future learning (pp. 27-42). Heidelberg, Germany: Springer.

Sims, R., Dobbs, G., \& Hand, T. (2002). Enhancing quality in online learning: Scaffolding planning and design through proactive evaluation. Distance Education, 23(2), 135-147. doi:10.1080/0158791022000009169

Turner, G. \& Brass, K. (2014, October). Mapping the humanities, arts and social sciences in Australia. Australian Academy of the Humanities, Canberra. Retrieved from https://www.humanities.org.au/wp-content/uploads/2017/04/AAH-Mapping-HASS2014.pdf 